\title{
The Use of Amides as Nitrogen Sources by Aspergillus nidulans
}

\author{
By M. J. HYNES* AND J. A. PATEMAN \\ School of Biological Sciences, Flinders University of South Australia, \\ Bedford Park, South Australia 5042 \\ (Accepted for publication 26 August 1970) \\ SUMMARY
}

The utilization of amides as nitrogen sources by Aspergillus nidulans has been studied. Formamide is hydrolysed by a specific formamidase enzyme. A second amidase is responsible for the utilization of acetamide, acrylamide, glycolamide and glycineamide. Propionamide, butyramide, valeramide and hexamide are also substrates for this enzyme, but other enzymes may contribute to their use as nitrogen sources. The aromatic amides, benzamide, phenylacetamide and nicotinamide are good nitrogen sources, but are probably not substrates for the acetamidase. Methyl carbamate and malonamide are neither substrates for the acetamidase nor serve as sole sources of nitrogen for $A$. nidulans. $\beta$-Hydroxypropionamide, lactamide and fumaramide are very poor nitrogen sources and are probably not substrates for the acetamidase. $\mathrm{N}$-substituted amides are not nitrogen sources.

A large number of amides including non-substrate amides, induce formamidase or acetamidase or both. Acrylamide, although a good substrate for the acetamidase, does not induce its synthesis.

\section{INTRODUCTION}

Amidase enzymes (acylamide-amidohydrolase, EC 3.5. I.4) hydrolyse amides and produce the corresponding carboxylic acid and ammonia. They have been described in rabbit liver extracts (Bray, James, Thorpe \& Wasdell, 1950) and various species of mycobacteria (Draper, I967; Halpern \& Grossowicz, I957; Kimura, 1959; Nagayama, Konno \& Oka, 196I). Some fungi can use amides as sources of carbon or nitrogen and possess amidases (Zittle, I95I; Steiner, 1959). In Pseudomonas aeruginosa a single amidase enzyme was found to hydrolyse a number of amides. The enzyme was inducible by certain amides and subject to catabolite repression (Kelly \& Clarke, I962). Mutant strains, altered in the regulation of amidase synthesis, have been isolated (Brammar, Clarke \& Skinner, 1967).

The observation that acetamide was a good nitrogen source for Aspergillus nidulans led to a study of amide utilization and amidase synthesis. A survey of amides was made to assess the number and substrate specificities of amidase enzymes and mutants altered in their ability to utilize amides were isolated.

* Present address: Department of Molecular Biology, University of Edinburgh, Edinburgh, Scotland. 


\section{METHODS}

Strains. The wild-type strain was biI, a biotin auxotroph, originating from the Department of Genetics, University of Glasgow. The isolation of mutants altered in amidase synthesis has been described elsewhere (Hynes \& Pateman, 1970a, b).

Chemicals and media. Analytical grade chemicals were used. Media were as described by Pontecorvo et al. (1953) and Cove (I963). Supplements were stored at $4^{\circ}$ as concentrated sterile solutions. Solutions of amides (Fluka Co.) were sterilized by Seitz filtration. Growth tests were carried out as described by Cove (1963). Plates were incubated at $35^{\circ}$ for 2 to 4 days.

Growth of mycelium for enzyme assays. Mycelium was grown in $200 \mathrm{ml}$. of medium in I 1 . flasks shaken at $25^{\circ}$ (Cove, I966) and harvested by filtration through nylon net, washed with water, blotted dry and frozen.

Preparation of cell-free extracts. These were prepared as described by Cove (1966). All extracts were made in 100 mM-tris- $\mathrm{HCl}$ buffer, $\mathrm{pH} 7 \cdot 2$, and centrifuged at about $70,000 \mathrm{~g}$ for 25 to $35 \mathrm{~min}$. in a refrigerated centrifuge. Protein was determined by the Folin method (Lowry, Rosebrough, Farr \& Randall, I95I) and was usually I to $2 \mathrm{mg} . / \mathrm{ml}$. of extract.

Enzyme assays. The amidase assay, which was based on the ammonia determination method of Muftic (1964), has been described elsewhere (Hynes, 1970). All substrate amides were used at concentrations of 10 to $20 \mathrm{~mm}$ in the reaction mixture.

Enzyme activities are expressed in nmoles of ammonia released $/ \mathrm{min} . / \mathrm{mg}$. protein.

\section{RESULTS}

Growth of the wild type on amides as sole nitrogen sources

Amides (at concentrations of Io to $50 \mathrm{~mm}$ ) were added as sole nitrogen sources to glucose-minimal medium. Growth of Aspergillus nidulans on the amides was compared with the sparse 'nitrogen-free' growth of the organism on media lacking a nitrogen source. Formamide, acetamide, propionamide, butyramide, valeramide, hexamide, glycineamide, glycolamide, benzamide, phenylacetamide and nicotinamide were good nitrogen sources. Nicotinamide was a nitrogen source, but resulted in abnormal, inhibited growth. $\beta$-Hydroxypropionamide, lactamide and fumaramide were only very poor nitrogen sources. Acrylamide, malonamide, methyl-carbamate and $\mathrm{N}$-substituted amides ( $\mathrm{N}$-methylformamide, $\mathrm{N}$-methylacetamide, $\mathrm{N}$-ethylformamide, $N$-methylpropionamide, $N$-ethylacetamide, $N, N$-dimethylformamide and $N, N$-dimethylacetamide) were not nitrogen sources for $A$. nidulans.

Interaction between amides as nitrogen sources. Amides which were not nitrogen sources were tested for inhibition of growth when acetamide or formamide was the sole nitrogen source. Malonamide, methyl-carbamate, $N$-methylformamide, $N$ methylacetamide, $N$-ethylformamide, $N$-methylpropionamide and $N, N$-dimethylacetamide at concentrations of 10 to $50 \mathrm{~mm}$ did not affect growth on acetamide (concentrations of Io to $50 \mathrm{~mm}$ ). Similarly, Io mM methyl-carbamate, malonamide, $\mathrm{N}$-ethylformamide, $\mathrm{N}$-methylformamide, $\mathrm{N}$-methylacetamide and $\mathrm{N}, \mathrm{N}$-dimethylformamide did not affect growth on $10 \mathrm{mM}$-formamide. Thus the non-utilizable amides did not inhibit either uptake or hydrolysis of acetamide or formamide.

Description of mutants. The isolation of mutants altered in amidase synthesis has 
been described elsewhere (Hynes \& Pateman, 1970). The mutants used to investigate the utilization of amides were: (a) $f m d S^{-}$I, unable to grow on formamide as a nitrogen source and lacking amidase activity with formamide as a substrate; $(b)$ amd $S^{-}$mutants, unable to grow on acetamide and lacking amidase activity with acetamide as a substrate; $(c) a m d R^{c}$ mutants, able to grow on acrylamide and to grow very strongly on acetamide as a nitrogen source. These mutants have high, partly constitutive acetamidase activities.

Table I. Growth of wild-type and mutant strains on various amides as sole nitrogen sources added to glucose-minimal medium

\begin{tabular}{|c|c|c|c|c|c|}
\hline \multirow[b]{2}{*}{ Nitrogen source* } & \multicolumn{5}{|c|}{ Strain } \\
\hline & Wild type & $a m d R^{c_{2}}$ & $a m d S^{-} 17$ & $f m d S^{-} \mathbf{I}$ & $a m d S^{-} \mathbf{I} 7 ; f m d S^{-} \mathbf{I}$ \\
\hline Formamide & + & + & + & 0 & 0 \\
\hline Acetamide & + & +++ & 0 & + & 0 \\
\hline Propionamide & + & ++ & \pm & + & \pm \\
\hline Butyramide & + & ++ & \pm & + & \pm \\
\hline Valeramide & + & + & \pm & + & \pm \\
\hline Hexamide & + & ++ & $\dot{+}$ & + & + \\
\hline Glutamine & + & + & + & . & . \\
\hline Asparagine & + & . & + & . & . \\
\hline Glycolamide & + & ++ & 0 & + & 0 \\
\hline Glycineamide & + & ++ & 0 & + & 0 \\
\hline Benzamide & + & + & + & \pm & \pm \\
\hline Phenylacetamide & + & + & \pm & \pm & \pm \\
\hline$\beta$-Hydroxypropionamide & \pm & \pm & \pm & \pm & \pm \\
\hline Lactamide & \pm & \pm & \pm & \pm & \pm \\
\hline Fumaramide & \pm & \pm & \pm & \pm & \pm \\
\hline Nicotinamide & $\overline{+}$ & $\overline{+}$ & $\bar{t}$ & - & - \\
\hline Urea & + & + & + & $\dot{t}$ & $i$ \\
\hline
\end{tabular}

Symbols on different media are not equivalent. $+++=$ Very strong growth; $++=$ strong growth; $+=$ growth; $\pm=$ poor growth; $O=$ 'nitrogen-free' growth.

Growth properties of mutants on amides. Table I shows the growth of the wildtype and mutant strains on various amides as nitrogen sources. All strains except those containing the $f m d S^{-}$I mutation grew well on formamide. The $f m d S^{-}$I mutant grew as well as the wild type on all other amides except benzamide and phenylacetamide. These results indicated that there was an amidase specific for formamide as a substrate, i.e. a formamidase. The effect of the $f m d S^{-}$I mutation on benzamide and phenylacetamide utilization may have been the result of formamide being a product of their breakdown rather than their being substrates for the formamidase.

The amd $S^{-}$mutation resulted in inability to grow on acetamide, glycolamide and glycineamide, but did not affect growth on formamide. This indicated that there was an amidase, called an acetamidase, which was solely responsible for the utilization of these amides. amd $R^{c}$ mutants have high acetamidase activities and were found to grow better on these three amides than did the wild type.

Propionamide, butyramide, valeramide and hexamide were clearly substrates for the acetamidase, since growth of the $a m d S^{-}$mutants was significantly less on these amides than that of wild type. In addition, the $a m d R^{c}$ mutants grew better than wild type on these amides. There appeared to be other pathways for the utilization of 
these amides because $a m d S^{-}$and $a m d S^{-} f m d S^{-}$strains could grow reasonably well on them, and growth on hexamide was particularly strong. The amd $S^{-}$and $a m d R^{c}$ mutations also appeared to affect growth on phenylacetamide. However, it cannot be excluded that this was caused by production of acetamide from phenylacetamide.

$\beta$-Hydroxypropionamide, lactamide and fumaramide were extremely poor nitrogen sources for all strains and so may not have been substrates for either the formamidase or the acetamidase. Urea, asparagine and glutamine were very good nitrogen sources for Aspergillus nidulans, and growth on these was not affected in any of the mutants tested, which indicated that the acetamidase and formamidase enzymes did not contribute significantly to their utilization. The $a m d S^{-}$mutation did not affect growth on nicotinamide and so this amide was probably not a substrate for the acetamidase.

Enzyme assays with different amides as substrates. The amidase assay used can be applied to all potential substrates capable of releasing ammonia. It was therefore possible to compare the hydrolysis of a variety of amides by crude extracts with that of acetamide.

Table 2. Amidase activities of the wild type grown on amides as nitrogen sources

\begin{tabular}{|c|c|c|c|c|c|c|c|}
\hline \multirow[b]{2}{*}{ Substrate* } & \multicolumn{7}{|c|}{ Nitrogen source $\dagger$} \\
\hline & Urea & $\begin{array}{l}\text { Form- } \\
\text { amide }\end{array}$ & $\begin{array}{l}\text { Acet- } \\
\text { amide }\end{array}$ & $\begin{array}{l}\text { Propion- } \\
\text { amide }\end{array}$ & $\begin{array}{l}\text { Butyr- } \\
\text { amide }\end{array}$ & $\begin{array}{l}\text { Valer- } \\
\text { amide }\end{array}$ & $\begin{array}{l}\text { Hex- } \\
\text { amide }\end{array}$ \\
\hline Formamide & $2 \mathrm{I}$ & 107 & 132 & 162 & 173 & 248 & 293 \\
\hline Acetamide & I4 & I I 4 & 103 & $7 \mathrm{I}$ & 76 & 76 & 90 \\
\hline Propionamide & 31 & 106 & 83 & 73 & 105 & 120 & II 3 \\
\hline Butyramide & 28 & 95 & 83 & $8 \mathrm{I}$ & I 13 & 120 & II 2 \\
\hline Hexamide & $2 \mathrm{I}$ & 79 & 70 & 63 & 90 & 105 & I66 \\
\hline
\end{tabular}

Methyl carbamate and malonamide gave less than $5 \%$ of the activity with acetamide in extracts of wild-type and $a m d R^{c}$ strains. Therefore these amides were not nitrogen sources probably because they were not substrates for an amidase enzyme. Acrylamide gave 70 to $80 \%$ of the activity with acetamide as a substrate in a number of extracts of wild-type and $a m d R^{c}$ strains. Since $a m d R^{c}$ mutants have increased acetamidase levels, this showed that acrylamide was a good substrate for the acetamidase and that other enzymes did not contribute significantly to its hydrolysis. Acrylamide was not a nitrogen source for wild type Aspergillus nidulans and, as shown below, this was caused by its lack of inducer activity.

Table 2 shows the activities of extracts of wild-type mycelia that has been grown on a number of amides as nitrogen sources with these same amides used as substrates. Growth on all the amides caused increased amidase activities compared with the activity on urea. The propionamidase, butyramidase and hexamidase activities of mycelia grown on urea were higher than the acetamidase activity, while these activities of mycelia grown on formamide and acetamide were slightly lower than the acetamidase activity. In mycelia grown on the other amides, activities were similar to or higher than the corresponding acetamidase activities. Notably there was a considerably higher hexamidase activity in extracts of mycelia grown on hexamide.

Table 3 shows the activities with different amides as substrates in extracts of mutants 
with altered acetamidase activities. The $a m d R^{c}$ mutant, which had higher acetamidase activities than the wild type, also showed higher activities with the other amides as substrates, although they were generally much lower than the corresponding acetamidase activities. These results are in agreement with the finding that $a m d R^{c}$ mutants grew better than the wild type on these amides as nitrogen sources, indicating that propionamide, butyramide, valeramide and hexamide were substrates for the acetamidase.

Table 3. Amidase activities of wild-type, amdS ${ }^{-} 17$ and amdR 6 strains grown on urea plus various amides

\begin{tabular}{|c|c|c|c|c|c|c|c|}
\hline & & & & rogen sour & & & \\
\hline $\begin{array}{l}\text { Substrate* } \\
\text { Wild type }\end{array}$ & Urea & $\begin{array}{c}\text { Urea } \\
+ \\
\text { form- } \\
\text { amide }\end{array}$ & $\begin{array}{c}\text { Urea } \\
+ \\
\text { acet- } \\
\text { amide }\end{array}$ & $\begin{array}{c}\text { Urea } \\
+ \\
\text { propion- } \\
\text { amide }\end{array}$ & $\begin{array}{c}\text { Urea } \\
+ \\
\text { butyr- } \\
\text { amide }\end{array}$ & $\begin{array}{c}\text { Urea } \\
+ \\
\text { valer- } \\
\text { amide }\end{array}$ & $\begin{array}{l}\text { Urea } \\
+ \\
\text { hex- } \\
\text { amide }\end{array}$ \\
\hline Acetamide & 27 & $4 I$ & 55 & 30 & 23 & 29 & 38 \\
\hline Propionamide & 24 & $3 I$ & 55 & 34 & 37 & 53 & 64 \\
\hline Butyramide & 46 & 50 & 96 & 43 & 45 & 51 & 58 \\
\hline Valeramide & 14 & 20 & 48 & 22 & 14 & 29 & 45 \\
\hline Hexamide & 29 & 25 & 43 & 27 & $2 I$ & 37 & 84 \\
\hline amd $S^{-} \mathrm{I} 7$ & & & & & & & \\
\hline Acetamide & 5 & 5 & 4 & 8 & 3 & 6 & 15 \\
\hline Propionamide & 2 I & 25 & 38 & 27 & 26 & 36 & 38 \\
\hline Butyramide & $2 \mathrm{I}$ & 15 & 18 & 22 & 26 & 23 & 38 \\
\hline Valeramide & I 6 & I I & $2 \mathrm{I}$ & 19 & 20 & 13 & 29 \\
\hline Hexamide & I 8 & 12 & 27 & 19 & 26 & 23 & 38 \\
\hline$a m d R^{c} 6$ & & & & & & & \\
\hline Acetamide & 222 & $38 I$ & 223 & 248 & 180 & 228 & I 80 \\
\hline Propionamide & 63 & 143 & III & 114 & 121 & I 54 & 210 \\
\hline Butyramide & 97 & 136 & 76 & 75 & 64 & 89 & 105 \\
\hline Valeramide & 75 & 122 & 46 & 87 & 64 & 75 & 105 \\
\hline Hexamide & 70 & I9I & 60 & I I I & 103 & 132 & 197 \\
\hline
\end{tabular}

The amd $S^{-}$mutant had very low acetamidase activities (close to the accurate limit of the assay), but significant activities with the other amides as substrates. Therefore hydrolysis of these amides could be accomplished by an enzyme (or enzymes) other than the acetamidase. This agreed with the growth tests which showed that strains containing $a m d S^{-}$would grow on propionamide, butyramide, valeramide and hexamide as nitrogen sources. There was not good evidence for induction of other amidase enzymes by the amides. In the amd $S^{-}$strain grown on urea plus amides the activities were similar to that of $a m d S^{-}$grown on urea alone. This point requires further investigation.

Induction of amidase enzymes by amides. A large number of amides were tested for inducer activity by growing mycelium on urea plus the amide being tested and comparing activities with those of mycelia grown on urea alone. A low concentration of urea $(\mathrm{I} \cdot 25 \mathrm{mM})$ was used to reduce the effects of repression, which was especially important in the control of the formamidase. Most amides were not very good inducers of amidase enzymes (Table 4). However, $N$-methylacetamide was a good inducer of both activities, while $\beta$-hydroxypropionamide, which was a very poor nitrogen source 
and probably not a substrate for the acetamidase, was a very good inducer of the acetamidase but not of the formamidase. Benzamide, which was a very good nitrogen source, induced both enzymes. However, it is not known if this was due to benzamide itself, or to some breakdown product. Another aromatic amide, nicotinamide, was not an inducer.

Table 4. The induction of the acetamidase and the formamidase in wild type by various amides

\begin{tabular}{|c|c|c|}
\hline \multirow[b]{2}{*}{ Inducing amide* } & \multicolumn{2}{|c|}{ Induction ratio $\dagger$} \\
\hline & Acetamidase & Formamidase \\
\hline Acetamide & $2 \cdot 5$ & $2 \cdot 1$ \\
\hline Fumaramide & $r \cdot 4$ & 0.8 \\
\hline$\beta$-Hydroxypropionamide & $3 \cdot 7$ & $I \cdot 0$ \\
\hline Lactamide & $I \cdot 3$ & 0.6 \\
\hline Methyl carbamate & $\mathbf{I} \cdot \mathbf{2}$ & $r \cdot 6$ \\
\hline Benzamide & $3 \cdot 6$ & $2 \cdot 0$ \\
\hline Nicotinamide & $1 \cdot 0$ & 0.8 \\
\hline$N$-methylacetamide & $2 \cdot 0$ & $\mathrm{I} \cdot 8$ \\
\hline$N$-methylformamide & $\mathrm{I} \cdot 7$ & $I \cdot I$ \\
\hline$N, N$-dimethylformamide & $I \cdot I$ & - \\
\hline$N$-ethylacetamide & $I \cdot O$ & 一 \\
\hline
\end{tabular}

Table 5. Summary of the utilization of amides by the acetamidase and formamidase enzymes

Amide

$\begin{array}{ccccc}\text { Nitrogen } & \begin{array}{c}\text { Substrate } \\ \text { for }\end{array} & \begin{array}{c}\text { Substrate } \\ \text { for }\end{array} & \begin{array}{c}\text { Inducer } \\ \text { of }\end{array} & \begin{array}{c}\text { Inducer } \\ \text { of }\end{array} \\ \text { source } & \text { formamidase } & \text { acetamidase } & \text { formamidase } & \text { acetamidase }\end{array}$

\section{Formamide}

Acetamide

Propionamide

Butyramide

Valeramide

Hexamide

Glycolamide

Glycineamide

Benzamide

Phenylacetamide

Nicotinamide

$\beta$-Hydroxypropionamide

Lactamide

Fumaramide

Acrylamide

Malonamide

Methylcarbamate

$N$-methylformamide

$N$-methylacetamide

$N$-ethylformamide

$N$-methylpropionamide

$N$-ethylacetamide

$N, N$-dimethylformamide

$N, N$-dimethylacetamide

$\begin{array}{cc}+ & + \\ + & + \\ + & + \\ + & + \\ + & + \\ + & + \\ \text { n.d. } & + \\ \text { n.d. } & + \\ +? & + \text { ? } \\ \text { n.d. } & \text { n.d. } \\ - & - \\ - & + \\ - & \pm \\ - & \pm \\ \text { n.d. } & - \\ \text { n.d. } & \text { n.d. } \\ + & \pm \\ - & + \\ + & + \\ \text { n.d. } & \text { n.d. } \\ \text { n.d. } & \text { n.d. } \\ \text { n.d. } & - \\ \text { n.d. } & - \\ \text { n.d. } & \text { n.d. }\end{array}$

n.d. $=$ Not determined $+=$ yes $\pm=$ weak $-=$ no. 
The above results were complicated by repression of the acetamidase by glucose (Hynes, 1970). Therefore induction experiments were carried out in carbon-free medium. Under these conditions acetamide and $\beta$-hydoxypropionamide, but not acrylamide, were found to induce the acetamidase. This therefore explained why acrylamide, although a good substrate for the enzyme, was not a nitrogen source for Aspergillus nidulans.

Summary of amide utilization. Table 5 summarizes amide utilization by Aspergillus nidulans. Some of these data are based solely on growth tests, and negative results in particular should be regarded with caution. Uptake of amides may complicate some of the conclusions about the amides which were not nitrogen sources. However, the inducing activity of amides such as methylcarbamate, $N$-methylacetamide and $\beta$ hydroxypropionamide suggested that these were taken up to some extent. Preliminary experiments on the uptake of $\left[{ }^{14} \mathrm{C}\right]$ acetamide were carried out with wild-type and $a m d S^{-}$strains. No accumulation of acetamide was found and so $A$. nidulans may lack an uptake system for acetamide.

\section{DISCUSSION}

Aspergillus nidulans has been shown to possess an amidase specific for formamide as a substrate and a second amidase responsible for the utilization of acetamide and a number of other amides. Other enzymes contribute to the utilization of longer chain amides and aromatic amides; possibly hydrolysis of longer chain amides occurs as a side reaction of such enzymes as esterases or proteases. Aromatic amides may be broken down without hydrolysis of the amide group. Some fungi can metabolize aromatic compounds (Cain, Bilton \& Darrah, 1968).

Asparagine and glutamine are not substrates for the formamidase or the acetamidase There may be a specific asparaginase and a specific glutaminase for the utilization of these amides. Aspergillus nidulans possesses a urease enzyme, which is lacking in mutants unable to grow on urea as a nitrogen source. These mutants map at loci distinct from the amdS and $f m d S$ loci (Scazzocchio \& Darlington, 1968).

A large number of amides (including $\mathrm{N}$-substituted amides) are not nitrogen sources for Aspergillus nidulans. N-substituted amides may not be substrates for amidase enzymes, since it is known that $A$. nidulans can use amines (which would be the products of hydrolysis of $\mathrm{N}$-substituted amides) as nitrogen sources (Arst \& Cove, 1969).

Many amides can act as inducers of the formamidase and acetamidase enzymes. These include both substrate and some non-substrate amides. Induction of the formamidase is not specific, although this enzyme is specific for formamide as a substrate. The inducer specificities of the acetamidase and the formamidase are similar but not exactly the same, e.g. $\beta$-hydroxypropionamide is a good inducer for the acetamidase, but not for the formamidase. Acrylamide, although a good substrate for the acetamidase, is not an inducer of its synthesis and is consequently not a nitrogen source. This allows the isolation of regulatory mutants producing the acetamidase constitutively (Hynes \& Pateman, 1970a,b).

The use of amides by Aspergillus nidulans contrasts with that by Pseudomonas aeruginosa where there appears to be only one amidase which is most active with acetamide and propionamide; formamide is a poorer substrate (Kelly \& Clarke, 1962). This enzyme, in addition to having hydrolytic amidase activity, also has acyl group transferase activity with hydroxylamine as an acyl acceptor, and consequent 
formation of hydroxamates. Preliminary evidence (M. J. Hynes \& P. J. Wright, unpublished) suggests that the $A$. nidulans acetamidase also has transferase activity. Variations in the acetamidase activity of extracts of wild-type, amdS $S^{-}$and $a m d R^{c}$ strains corresponded with parallel variations in transferase activities. There appears to be a single amidase in Mycobacterium smegmatis with activity for formamide and butyramide (Draper, 1967). In this case the amidase activity can be dissociated from transferase activity. In animal tissues, an amidase has been shown to have greatest activity with amides with 5 to 7 carbon atoms (Bray et al. 1950).

\section{REFERENCES}

ARST, H. N. \& COVE, D. J. (1969). Methylammonium resistance in Aspergillus nidulans. Journal of Bacteriology 98, 1284-1293.

Brammar, W. J., Clarke, P. H. \& Skinner, A. J. (1967). Biochemical and genetical studies with regulator mutants of the Pseudomonas aeruginosa 8602 system. Journal of General Microbiology 47, 87-I02.

Bray, H. G., James, S. P., Thorpe, W. V. \& WASDell, M. R. (1950). The fate of certain organic acids and amides in the rabbit. II. Further observations on the hydrolysis of amides by tissue extracts. Biochemical Journal 47, 294-299.

Cain, R. B., Bilton, R. F. \& Darrah, J. A. (I968). The metabolism of aromatic acids by microorganisms. Metabolic pathways in the fungi. Biochemical Journal 108, 797-828.

Cove, D. J. (1963). Studies of the Biochemistry and Genetics of Inorganic Nitrogen Metabolism in Aspergillus nidulans. Ph.D. Thesis, University of Cambridge.

Cove, D. J. (I966). The induction and repression of nitrate reductase in the fungus Aspergillus nidulans. Biochimica et Biophysica Acta 113, 51-56.

DRAPER, P. (1967). The aliphatic acylamide amidohydrolase of Mycobacterium smegmatis: its inducible nature and relation to acyl transfer to hydroxylamine. Journal of General Microbiology 46, III-I23.

HALPERN, Y.S. \& Grossowicz, N. (1957). Hydrolysis of amides from mycobacteria. Biochemical Journal 65, 716-720.

Hynes, M. J. (1970). Induction and repression of amidase enzymes in Aspergillus nidulans. Journal of Bacteriology 103, 482-487.

HyNes, M. J. \& PATEMAN, J. A. J. (1970a). The genetic analysis of regulation of amidase synthesis in Aspergillus nidulans. I. Mutants able to utilize acrylamide. Molecular and General Genetics 108, 97-106.

Hynes, M. J. \& Pateman, J. A. J. (1970 $b$ ). The genetic analysis of regulation of amidase synthesis in Aspergillus nidulans. II. Mutants resistant to fluoracetamide. Molecular and General Genetics 108, 107-I I6.

Kelly, M. \& Clarke, P. H. (1962). An inducible amidase produced by a strain of Pseudomonas aeruginosa. Journal of General Microbiology 27, 305-316.

Kimura, T. (1959). Studies on metabolism of amides in Mycobacteriaceae. III. Amidases and transferases in extracts from Mycobacteriaceae. Journal of Biochemistry, Tokyo 46, I271-I 279.

Lowry, O. H., Rosebrough, M. J., FarR, A. L. \& RANDALl, R. J. (I95I). Protein measurement with the Folin phenol reagent. Journal of Biological Chemistry 193, 265-275.

Muftic, K. C. (1964). A new phenol-hypochlorite reaction for ammonia. Nature, London 201, 622-623.

Nagayama, H., KonNo, K. \& OKA, S. (1961). Formamidase in mycobacteria and its use in differentiating saprophytic mycobacteria from other mycobacteria. Nature, London I9o, I219-1220.

Pontecorvo, G., Roper, J. A., Hemmons, L. M., Macdonald, K. D. \& Bufton, A. W. J. (1953). The genetics of Aspergillus nidulans. Advances in Genetics 5, I4I-238.

SCAZzocchio, C. \& Darlington, A. J. (1968). The induction and repression of the enzymes of purine breakdown in Aspergillus nidulans. Biochimica et Biophysica Acta 166, 557-568.

STEINER, M. (1959). The utilization of amino and amide nitrogen by Endomycopsis vernalis and other yeasts (with special reference to metabolic reactions at the surface of the cells). Symposia of the Society for Experimental Biology 13, 177-192.

ZrTTLE, C. (1951). Hydrolysis of acid amides and amino acid amides. In The Enzymes, vol. I, part 2, p. 922. Edited by J. B. Sumner and K. Myrback. New York: Academic Press. 